Demiryolu Mühendisliği

Temmuz 2021

Say1:14, Sayfa: 26-38

Araştırma Makalesi
Railway Engineering

July 2021

Issue:14, Page: $26-38$

Research Article

doi: 10.47072/demiryolu.869946

http://dergipark.org.tr/demiryolu

e-ISSN: 2687-2463, ISSN: 2149-1607

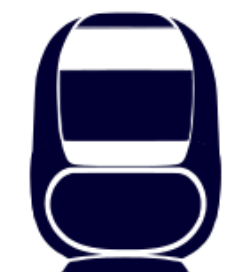

\title{
Lamine CFRP Donatılı Traverslerin Deneysel ve Sonlu Eleman Analizleriyle İncelenmesi
}

\author{
Ferhat ÇEÇEN*1®i), Bekir AKTAŞ2®i) \\ ${ }^{1}$ TCDD Sivas Beton Travers Fabrikası Müdürlügü, Sivas, Türkiye \\ ${ }^{2}$ Erciyes Üniversitesi, Mühendislik Fakültesi, Inşaat Mühendisliği Bölümü, Kayseri, Türkiye \\ *ferhatcecen@tcdd.gov.tr
}

(Alınış/Received: 28.01.2021, Kabul/Accepted: 28.03.2021, Yayımlama/Published: 31.07.2021)

\begin{abstract}
Öz: Günümüz demiryolu işletmeciliğinde artan hız ve aralıksız işletim koşulları sonucunda, daha düşük bakım gerektiren çözümler mecburiyet halini almıştır. Bu çalışmada, en önemli demiryolu yapı elemanlarından biri olan traversler ele alınmıştır. Klasik betonarme traverslerin literatürde geçen çeşitli sorunlarına değinildikten sonra bu sorunların kaynağında çözümlenmesi adına mevcut çelik donatılar yerine karbon fiber takviyeli polimerlerin (carbon fiber reinforced polymers, CFRP) kullanımı araştırılmıştır. CFRP donatı olarak da geleneksel dairesel donatı geometrisi yerine çok daha düşük maliyetli lamine form kullanılmıştır. Üretilen prototiplerde yapılan TS EN 13230-3 statik eğilme testleri ve detaylı ANSYS sonlu eleman analizlerine göre uzun ve verimli servis ömrü açısından oldukça olumlu sonuçlar elde edilmiştir.
\end{abstract}

Anahtar kelimeler: Demiryolu traversleri, Karbon fiber takviyeli polimer, Sonlu eleman analizi, Düşük bakımlı üstyapı, Sürdürülebilir ulaştırma

\section{Experimental and Finite Element Investigation of Laminated Carbon Fiber Reinforced Polymer Reinforced Railway Sleepers}

\begin{abstract}
In today's railway operations, as a result of increasing operating speeds and uninterrupted operating conditions, solutions that require less maintenance have become obligatory. In this study, sleepers, one of the most important railway building elements, are discussed. After presenting the various problems of conventional concrete sleepers mentioned in the literature, the use of carbon fiber reinforced polymers (CFRP) instead of existing steel reinforcements was investigated to solve these problems at the source. As CFRP reinforcement, a much lower cost laminated form is used instead of traditional circular reinforcement geometry. Static bending tests according to TS EN 13230-3 and detailed ANSYS finite element analysis were performed on the produced prototypes, and very positive results were obtained in terms of long and efficient service life.
\end{abstract}

Keywords: Railway sleepers, Railroad ties, Carbon fiber reinforced polymer, Finite element analysis, Low maintenance superstructure, Sustainable transportation

\section{Giriș}

Çağımızda geçmişten çok daha yüksek hızlarla ve kapasitelerle işletilen demiryollarının yapım, bakım ve işletim esaslarında köklü değişimler söz konusudur. Düşük karbon emisyonu sayesinde, demiryollarını en çevreci ulaşım tipi haline getiren elektrifikasyon sistemleri ile insan hatalarını önleyerek demiryollarını en güvenli ulaşım tipi haline getiren sinyalizasyon sistemleri tüm dünyada giderek yaygınlaşmıştır. Demiryolu taşıtlarının işletmesinde kullanılan enerji biçimleri ve güvenlik sistemleri değişmiş, elektrik yalıtkanlığ 1 ve manyetik nötrlük parametreleri önem kazanmıştır. Ayrıca daha sık tren seferleri etkisiyle oluşan milyonlarca yük tekrarına karşı, daha yüksek yorulma dayanımına ihtiyaç duyulurken, artan işletim hızlarının etkisiyle meydana gelen daha yüksek değerli darbe yükleri ve daha yüksek frekanslı titreşimler nedeniyle, yüksek sönümleme kabiliyeti ve rezonans direnci kavramları gündeme gelmiştir. Tüm bu gelişmeler ile geçmişten çok daha farklı tesirler altında kalan modern demiryollarında, hat bakım veya onarımı 
için ayrılabilecek süreler ise geceleri birkaç saatten ibarettir. Sonuç olarak; günümüz yüksek kapasiteli demiryolu işletmeciliğinde mümkün mertebe bakım gerektirmeyen çözümler mecburiyet halini almıştır.

Demiryolu üstyapı bileşenlerinden biri olan traversler, raylardan aldığ 1 yük ve titreşimleri, altyapıya sönümleyerek aktarmakta ve yol geometrisini korumakta büyük öneme sahiptir. Geçmişten günümüze demiryollarında traversler her türlü dış etkene açıktır ve modern demiryollarında daha yüksek değerli ve yüksek tekrarlı darbe yüklerine maruz kalan klasik betonarme traverslerde sıklıkla çatlaklar gözlenmektedir. Örneğin İsveç’te çıplak gözle 3 milyon traversin çatlak muayenesinin yapıldığı bir araştırmaya göre, 500 bin adedinde gözle görülebilir (makroskobik) çatlaklar tespit edilmiştir [1]. Demiryolu traverslerinde ilk çatlakların oluştuğu taban kısmı tamamen balasta gömülüdür. Bu yüzden, traversin taban kısmının incelenmesi imkânı olan yol yenileme çalışmaları esnasında tespit edilen bu \%17'lik dilimin, demiryolu üzerinde yürüyerek yapılan sıradan gözle muayeneler esnasında tespit edilmesi mümkün olmayacaktır. Demiryolu traversleri her türlü dış etkene açık olduğundan, bu çatlaklardan sızan su-nem-klorid iyonu maruziyeti ile mevcut traverslerde kullanılan çelik donatıların korozyona uğrama riski bulunmaktadır. Örneğin, Litvanya demiryollarında yalnız 3 yıl süreyle kullanılmış traverslerin donatı korozyon düzeyinin araştırıldığı deneysel bir çalışmada, traverslerde mevcut korozyon kaynaklı hasarın 40 mm'lik çapta bir alana yayıldığı kaydedilmiştir [2]. Korozyon nedeniyle hem donatı-beton ara yüzünde aderans kayıpları meydana gelmekte, hem de donatı kesit alanı düşmektedir. Ayrıca öngerilmeli traverslerde daha düşük çaplı donatılar kullanıldığından, minimal korozyon maksimal kapasite kayıpları doğurmaktadır [3]. Modern demiryollarında kullanılan elektrifikasyon sistemleri nedeniyle, betonarme yapılarda görülen korozyon mekanizması daha da hızlanmaktadır. Elektrifikasyonlu hatlardaki yaklaşık 30.000 voltluk yüksek gerilim taşıyan kablo hattındaki elektriğin bir kısmı, tren geçerken raylara ve traverslere de sirayet etmektedir. Elektrifikasyonlu hatlarda çelik rayların ve çelik donatı içeren traverslerin, elektrik akımı etkisiyle daha hızlı korozyona uğrayacağı konusunda literatürde detaylı bilgiler mevcuttur $[4,5]$. Bu açıdan traverslerde kullanılan donatının elektriksel açıdan yalıtkan olması ve korozyon direnci taşıması, traverslerin servis ömrü üzerinde kayda değer etkiye sahiptir. Bu parametrelere magnetik levitasyon vb. enerji sistemleri ile çalıştırılan demiryolları için de ihtiyaç duyulmakta, bunların yanı sıra manyetik nötrlük faktörü de eklenmektedir. Bunların dışında, modern demiryollarında insan hatalarının önlenmesi için çeşitli otomatik sinyalizasyon sistemleri geliştirilmiştir. $\mathrm{Bu}$ sistemlerde, demiryolu hattının tamamında veya seçilen bir bölümünde, raylara 20-30 Volt düzeyinde sinyal elektriği verilmektedir. Özel bir işletim sistemi ile demiryolu taşıtları anlık olarak izlenebilmekte veya taşıtların geçtiği lokasyonların bilgisi sisteme iletilmektedir. $\mathrm{Bu}$ sinyal takibinin demiryolu hatlarının tamamında sağlanması halinde ise gönderilen sinyallerin (ray kırı̆̆ $1 \mathrm{vb}$. nedenle) kesintiye uğradığı noktalar sürekli aktif takip edilebilmektedir. Ancak sinyalizasyon sistemlerinin çalışması için iki ray arasında elektrik yalıtkanlığı mükemmel olmalıdır. Yüksek elektrik iletkenliği gösteren çelik donatılar sinyalizasyon hatalarına sebebiyet verebildiğinden, sinyalizasyon sistem çeşidine bağlı olarak ihtiyaç duyulan lokasyonlarda daha yüksek maliyetli özel önlemler alınmaktadır $[4,6]$.

Sonuç olarak; belirtilen nedenlerle klasik betonarme traversler hedeflenen $40-50$ ylllik servis ömrüne ulaşamadan erken deforme olmaktadır. Bu durum tüm dünyada önemli düzeyde mali ve çevresel zararlar meydana getirmekte, demiryolu kuruluşlarının bütçelerinin önemli bir kısmı travers kaynaklı bakım çalışmalarına ayrılmak zorunda kalmaktadır [6]. Özellikle son 20-30 yıldır demiryolu işletim hızlarının ve sefer sayılarının artması ile tüm dünyada yapılan araştırmaların sayısı oldukça artmış, panel (floating slab track), çerçeve (frame), çift $\mathrm{H}$ (double-H), merdiven (ladder) tipi veya çeşitli balastsız üstyapı modelleri geliştirilmiş ve geliştirilmeye devam etmektedir. Söz konusu ar-ge çalışmaları standart demiryolu traverslerinden çok daha yüksek maliyetlerine rağmen yürütülmekte, sağlayacağı düşük bakım ihtiyacı ve yüksek hızlı-aralıksız demiryolu işletim şartlarına uyumluluk sağlaması gibi faydaların çok daha önemli olduğu belirtilmektedir [6]. 
Bu bağlamda ülkemizde de yakın zamanda çelik donatıların korozyon ve elektrik iletkenliği problemlerinin giderilmesi için dairesel karbon fiber takviyeli polimer donatılar (circular CFRP rebars) kullanılarak travers numuneleri üretilmiş ve pozitif sonuçlar elde edilmiştir [6]. Ancak inşaat sektöründe çok yakın zamanda kullanılmaya başlayan bu inovatif ürünlerin maliyeti sıradan inşaat mühendisliği yapıları için halen yüksektir. Yeni üretim teknolojilerinin gelişmesi ve üretim-tüketim düzeyinin artması ile bu maliyetin düşmesi beklenmekle birlikte günümüzde henüz yeterli fizibiliteye ulaşamadığı düşünülmektedir. Bu çalışma kapsamında yapılan piyasa araştırmalarına göre; öngerilmeli betonarme traverslerin çelik donatı maliyetleri 2020 yılı için 510 USD/travers dolaylarındadır. Eşdeğer yorulma dayanımına sahip travers dizaynında kullanılacak dairesel CFRP donatıların maliyeti ise; çeşitli firmalardan alınan fiyatlara göre 70120 USD/travers dolaylarındadır. CFRP donatıların yüksek çekme dayanımı, yorulma ömrü, korozyon direnci, elektrik yalıtkanlığ1 ve manyetik nötrlügü faydalarına rağmen; örneği verilen bu maliyet farkı nedeniyle, inşaat sektöründe tarihi yapıların ve önemli köprülerin güçlendirilmesi ile kıyı yapılarının inşası haricinde kullanımı yaygınlaşmamıştır.

Belirtilen mali dezavantajı gidermek için, 2020 yılı içerisinde, inşaat mühendisliği yapılarında kullanılan alışılageldik dairesel donatı geometrisinin dışına çıkılarak, fiber takviyeli polimer (fiber reinforced polymer, FRP) üretimi açısından ekonomi sağlayan plaka formundaki yerli CFRP lamine ürünler (CFRP laminates) kullanılarak, az sayıda travers numunesi üretilip öndeneyleri yapılmış ve olumlu sonuçlar elde edilmiştir [7]. Bu yöntem ile üretilecek traverslerin donatı maliyeti 2020 yılı için 8-11 USD/travers dolaylarındadır. Elde edilecek bu önemli mali faydanın yanı sıra, öngerilmesiz üretim metodu ile daha az işçilikle travers üretimi sağlanması, ayrıca elektrifikasyonlu/manyetik enerjili ve sinyalizasyonlu modern demiryolları açısından daha elverişli olması gibi önemli faydaları da söz konusudur.

$\mathrm{Bu}$ çalışma kapsamında, konunun daha detaylı araştırılması için söz konusu CFRP lamineler ile daha fazla varyasyonda travers prototipleri hazırlanıp, TS EN 13230-3 standardında geçen ray mesnedinde statik yüklemeli pozitif moment tayini deneyleri yapılmış ve ANSYS sonlu eleman modelleri oluşturularak yeni prosesin avantaj ve dezavantajları araştırılmıştır.

\section{Metot}

\subsection{Prototip traverslerin en kesit boyutlart ve donatı varyasyonlart}

$\mathrm{Bu}$ çalışma kapsamında yeni üretilecek traverslerde, mevcut rakipleriyle karşılaştırma için dünyada yaygın olarak kullanılmakta olan B70 tipi öngerilmeli ve U3 tipi öngerilmesiz çelik donatılı traversler ile benzer beton kesit boyutları kullanılmıştır. Bu prototiplerde donatı olarak, standart 4,9 mm kalınlığında ve $120 \mathrm{~mm}$ enindeki CFRP plakalar; 20, 25 ve $30 \mathrm{~mm}$ enlerinde kesilerek 3 varyasyonda 3'er adet travers üretilmiştir. Kullanılan CFRP plakaların Poisson oranı 0.33, çekme elastisite modülü $160 \mathrm{GPa}$, çekme dayanımı $1500 \mathrm{MPa}$ ve kesme dayanımı $60 \mathrm{MPa}$ olup, donatı ve kalıp düzeni literatürde geçen önceki çalışma ile eşdeğerdir [7].

\subsection{Prototip traverslerin üretimi ve uygulanan deney düzeni}

Üretilen prototip traverslerin ve üretim esnasında alınan beton numunelerinin TS EN 13230-1 doğrultusunda kür işlemi yapılmıştır. CFRP lamine plakalarla donatılandırılmış traverslerin üretimi esnasında kullanılan betondan küp ve silindir numuneler alınarak basınç ve yarmada çekme testleri yapılmış, prototip traversler 28 günlük kür süresi akabinde TS EN 13230-3 doğrultusunda "travers ray mesnedinde pozitif yüklemeli moment tayini" deneyine tabi tutulmuştur. Deney yöntemi ve ileride değinilecek yük limit terimleri şu şekildedir: Yükleme esnasında ilk çatlak tespit edilen $\left(\mathrm{Fr}_{\mathrm{r}}\right)$ veya demiryolu kuruluşunca belirlenen $\left(\mathrm{Fr}_{0}\right)$ yük değerine kadar yükleme yapılır. Daha sonra yük $10 \mathrm{kN}$ aralıklarla artırılarak 10 saniye ile 5 dakika arasında sabit tutulduktan sonra yük kaldırılıp, mercekle çatlak kontrolü yapılır. Bu şekilde 10'ar kN 
artışlarla yük kaldırıldığında, tamamen kapanmayıp 0,05 mm'lik kalınlıkta görülen çatlak tespit edilirse deneyin ikinci kayıt unsuru $\left(\mathrm{Fr}_{0,05}\right)$ bulunmuş olmaktadır. Son olarak, yükleme kaldırma prosedürüne devam edilerek, kesitin daha fazla yük taşıyamadığı, kırılma yükü $\left(\mathrm{Fr}_{\mathrm{B}}\right)$ kayıt edilir.

\subsection{Travers test düzeneğinin sonlu eleman modellemesi}

Traverslerde yapılan deneylerin sonlu eleman modellemesi için ANSYS ${ }^{\circledR}$ yazılımı kullanılmıştır. Traverslerin modellenmesinde yalnızca deney mesnetlerinin tesiri görülen travers yarı boyu modellenerek hesap kolaylığı sağlanmıştır. Lineer olmayan (non-linear) beton mekanik karakteristiklerin modellenmesi için Concrete NL materyali ve Drucker-Prager modeli kullanılmıştır. Traversler üzerinde yapılan deneysel çalışmalar 1şığında; ANSYS beton yumuşama (softening) parametrelerinden residual strength parametresi \%80, maksimum deformasyon düzeyi (plastic strain limits) polipropilen elyaf katkılar ve trapez travers kesit boyutları doğrultusunda \%0,996 olarak deneme-yanılma yöntemiyle belirlenmiştir. ANSYS beton modeli için ihtiyaç duyulan Poisson oranı, şekil değiştirmeler elastik sınırlar içerisinde kaldığı sürece sabit bir değere eşittir. Bu değer beton için yaklaşık 0.15-0.20'dir [8]. Literatürde eğilme altındaki kiriş elemanlar için ise 0,25 değerinde kullanımı yönünde çalışmalar bulunmaktadır [9]. Betonun poisson oranı donatı gerilimlerinin doğru hesaplanmasında da önemli etkiye sahip olup, bu çalışmada da traverslerin testler esnasında eğilme yüküne maruz kaldığ 1 ve basınç lobu daha düşük trapez travers kesit boyutları göz önünde bulundurularak 0,25 değeri kullanılmıştır. Betonun gerilme-deformasyon ilişkisinde Hognestad modelinden yararlanılarak betonda mikro-çatlak oluşumlarıyla plastik deformasyonların başladığı yük oranı \%40 olarak, C55/67 sınıfındaki yüksek beton dayanımı dolayısıyla beton için maksimum gerilmeye denk gelen plastik birim kısalma \%0,12 olarak hesaba katılmıştır. Literatürde betonun maksimum dayanımının \%70'i civarına erişildiğinde Poisson oranının da artmaya başladığı ve artan yükleme etkisi altında poisson oranının 0,5 değerini aşması halinde ise beton için dilatasyonun başladığı ve dilatasyon başlangıcının mikro-çatlakların oluşmasını ve/veya gelişmesini tetiklediği belirtilmektedir [8]. Aynı kaynakta belirtildiği üzere; bu yük seviyesinin üzerinde, Poisson oranı yerine dilatasyon oranı (dilatency rate) ifadesinden faydalanmak, durumu daha açı ifade etmek için gereklidir ve betonda maksimum gerilmeye denk gelinen yaklaşık \%0,2'lik deformasyon düzeyinde en büyük dilatasyon oranı olan 1,00 değerine ulaşılır [8]. Bu doğrultuda sargı donatısız, elyaf katkılı üretilen travers betonunu için ANSYS Drucker-Prager modelinde dilatasyon oranı simülasyonlardan sonra 0,90 olarak girilmiştir.

Sonlu eleman analizlerinde donatıların modellenmesinde yaygın olarak 3 yöntem uygulanmaktadır. Bunlar; donatı en kesit oranına dayalı, yayılmış donatı (semeared reinforcement) varsayımı; donatıların betonla birleşmiş aks elemanlar olarak varsayıldığı gömülü donatı (embedded reinforcement) varsayımı ve tamamen ayrı elemanlardan oluşan ayrık donatı (discrete reinforcement) varsayımlarıdır. Bu esnada, donatıların çoğunlukla eksenel yük taşıdığı varsayımına dayalı olarak genellikle tek boyutlu bağ (truss) elemanlar kullanılmaktadır. En etkili ayrık donatı yöntemi sayesinde donat1-beton ara yüzündeki aderansı modellemek için ayrı temas elemanları kullanılabilmektedir. Bu yöntemin dezavantajı ise sonlu eleman ağlarının (mesh) beton ve donatıda birbiriyle örtüşmelerinin sağlanması zorluğudur [9]. Bu çalışmada ise, bu üç modelin haricinde daha detaylı analiz sağlayan ayrı bir modelleme uygulanmıştır. Bu model sayesinde, yaygın donatı modellerinden en etkilisi olarak gösterilen ayrık (discrete) donatı varsayımında kullanılan tek boyutlu truss elemanlar yerine, üç boyutlu solid elemanlar kullanılmış ve donatıların maruz kalacağı tüm yükler hesaba katılabilmiştir. Travers en kesitinde, büyük betonarme yapılardakinden çok daha az hesaplanması gereken sonlu eleman bulunduğundan yakınsama (converge) işlemi mümkün olmuştur. Ayrıca donatı modellemelerinde büyük öneme sahip olan mesh örtüşmesi konusu, ANSYS programı ile birlikte gelen geometri yazılımı SpaceClaim yazılımında ortak topoloji (shared topology) opsiyonu uygulanarak kolayca sağlanabilmiştir. CFRP donatıların gerilme-deformasyon eğrileri oluşturulurken literatürde geçtiği üzere kırılma yüküne kadar lineer elastik davranış sergilediği varsayılmıştır. FRP (fiber 
reinforced polymer, fiber takviyeli polimer) donatılar çelik donatıların aksine akma davranışı sergilemeden nihai dayanıma erişmektedir [9]. FRP ürünlerin çekme dayanımı ve elastisite modülü bazı teknik bilgi föylerinde yanlışlıkla yalnız liflerin sahip olduğu değerler ile dile getirilmekte olup, bu konuya dikkat edilmesi gerekmektedir. Günümüz FRP üretim teknolojileri itibariyle optimum elyaf içeriği \%50-60 düzeylerinde olup, nihai ürünün dayanımı lif kullanım yüzdesine bağlı olarak değişmektedir. Ayrıca FRP ürünü içerisindeki liflerin kullanım yönlerine bağl1 olarak, FRP ürünlerin 3 eksendeki gerilme-deformasyon özelliği farklı (orthotropic) özellikler sergilemektedir. İşlem kolaylığı açısından önem arz etmediği durumlarda FRP ürünler isotropik lineer elastik olarak veya ortotropik lineer elastik olarak modellenebilmekte olup [10], bu çalışmada detaylı analizler yapılacağından tam simülasyon için ortotropik lineer elastik modelleme tercih edilmiştir. FRP kompozit ürünlerin göçme kriterleri belirlenirken ANSYS yazılımı birçok seçenek sunmaktadır. En çok kullanılanlarından bazıları, maksimum deformasyon kriteri, maksimum gerilme kriteri, Tsai-Wu ve Puck kriteridir [9]. Bu çalışmada, göçme tahkiki için (failure criteria) Tsai-Wu, Puck ve LaRc03/04 kriterleri tercih edilmiştir.

Daha önce değinildiği üzere; bu çalışmada gerek beton elemanların gerekse donatıların modellenmesinde ANSYS Solid 186 eleman tipi tercih edilmiştir. ANSYS sonlu eleman yazılımıyla geliştirilen modellerde günümüze kadar sıklıkla; beton malzeme için Solid 65, donatılarda ise link 180 ve beam 188 elemanları hesap kolaylığı açısından kullanılmıştır. Ancak bu çalışmada travers analizlerinin büyük inşaat yapıları kadar kompleks olmamasının sağladığı avantaj ile, detaylı analiz sağlayan Solid 186 eleman tipi tercih edilmiştir. Bu yüksek nitelikli elemanlar; 3 boyutlu, 20 noktaya ve quadratik deformasyon kabiliyetine sahiptir. Söz konusu 20 ayrı noktanın her birinin 3 eksende serbestliği bulunmakta olup, plastisite, hiperelastiklik, sünme, geniş deformasyon (large deflections), öngerilmeli tasarım ve katmanlı kompozit modelleme avantajları sunmaktadır [11]. Beton elemanların modellenmesinde halen kullanılan solid 65 elemanının ise 8 nokta kapasitesi olup, özellikle ani ve/veya yüksek değerli yüklemeler halinde yakınsama (convergence) problemleri ortaya çıkarmakta ve çözüme ulaşılamamaktadır. Ayrıca yayılmış (semeared) donatı uygulanması halinde donatılarda kesme kuvvetleri hesaba dâhil edilmemektedir. $\mathrm{Bu}$ ve benzeri nedenlerle ANSYS tarafından daha güncel Solid $185 \mathrm{vb}$. elemanların kullanılması tavsiye edilmektedir [11]. Donatıların modellenmesinde halen kullanılan link 180 eleman 2 nokta içermekte olup, link elemanlarında kesme gerilmeleri, gerilme gradyanları ve deformasyonlar ihmal edilmektedir. Bu ve benzeri nedenlerle, gerekli durumlarda Timoshenko kiriş teorisine dayalı beam 188/189 vb. elemanların kullanılması tavsiye edilmektedir [11]. Beam elemanları 2 veya 3 nokta içermekte olup, her noktanın 6 veya 7 serbestlik derecesi bulunmaktadır. 7. serbestlik bükülme ile ilgilidir. Ancak bu elemanlarla yapılan modellemelerde en kesit alanındaki dikey kesme (transverse-shear) sabit kabul edilmektedir. $\mathrm{Bu}$ yüzden kesme gerilmelerinin dağılımının önem arz ettiği uygulamalarda önerilmemekte, bu alanlarda solid elemanların kullanımı önerilmektedir [11].

Solid 186 elemanı ile belirtilen avantajların tam olarak elde edilebilmesi ve yakınsama (convergence) sorunu yaşanmaması için literatürde önerildiği üzere kare/dikdörtgen ağırlıklı (hex dominated) mesh yapılandırması uygulanmıştır [12]. Hexahedron elemanlar katı (solid) ve yüzey modellemede en çok tercih ve tavsiye edilen eleman türüdür. Hexagonal elemanlar kullanılması eleman sayısının ve çözüm süresinin azalmasını sağlar [13]. Sonlu eleman mesh boyutları gerilmelerin yüksek veya düşük çıkmasında önemli etkiye sahiptir. Gereğinden küçük mesh boyutu kullanımı enerji dağılımını azalttığı için kırılma yükünü gerçekte olduğundan daha az, gerektiğinden büyük mesh kullanımı halinde de çatlak gelişimini düşürdügü için kırılma yükünü gerçekte olduğundan daha yüksek hesaplayabilmektedir [14]. Ayrıca sonlu elemanların en-boy oranının (aspect ratio) uygun seçilmemesi halinde hatalar meydana gelmektedir. Elemanların enboy oranı birbirine ne kadar yaklaşırsa o kadar kaliteli bir mesh işlemi sağlanır [15]. Bu doğrultuda (maksimum iri agrega boyutu ile eşdeğer olarak) maksimum mesh boyutu $25 \mathrm{~mm}$ ve en-boy oranı olarak 1 değerleri kullanılmıştır. Tüm bu parametre seçimleri ile birlikte, özellikle birden fazla parçanın temas yüzeylerinde sonlu eleman ağlarının örtüşmesinin önemi bir kat daha 
artmaktadır. Uyumsuz bir ara yüzey gerçek olmayan yüksek gerilimlerin oluşmasına neden olur. Özellikle ara yüzeylerde düğüm noktalarının (node) tam olarak çakışması ya da uyumlu olması ile gerilimlerin bir yüzeyden diğerine doğru olarak aktarılmasını sağlar [13]. SpaceClaim uygulamasındaki shared topology özelliği sayesinde beton ve donatı elemanlarının mesh bağlantıları birbirleriyle mükemmel örtüşmektedir. Mesh işleminin değerlendirilmesi aşamasında skewness kriteri en çok kullanılan ve geçerliliği olan bir kriterdir ve 0,25-0,50 değerleri iyi bir mesh kalitesi olarak kabul edilirken, 0,94'e kadar kabul edilebilir bir kalitede, bunun üzerinde ise kötü ve kalitesiz bir meshten söz edilebilir [13]. Yapılan analizlerde seçilen parametreler akabinde mesh kalitesi ANSYS tarafindan skewness cinsinden 0,419 olarak hesaplanmış ve kabul edilebilir kalitede olduğu görülerek analizlere devam edilmiştir.

Travers testleri esnasında mesnet koşullarının doğru tanımlanması doğru ve tek bir çözüm elde edilmesi açısından büyük önem taşımaktadır. TS EN 13230-3 testlerinde mesnetler 10' ar cm genişliğinde, eğilme yönünde dönebilen dikdörtgen temas yüzeyine sahip olup, ayrıca lokal ezilmeleri azaltmak adına plastik ara yüzler kullanılmaktadır. Bu kapsamda çeşitli mesnet koşulları için analiz simülasyonları gerçekleştirilmiş ve uygulanan deneyle örtüşen mesnet koşulunun her iki mesnette yatay (UY) harekete ve X aksında dönmeye izin verilen 10 'ar cm eninde remote displacement mesnetler ve hidrolik pres yükleme aksamiyla ray mesnedinde yalnızca dikey (UZ) yönde harekete izin verilen remote force ve her üç ara yüzeyde de plastik ara elemanları temsilen rigid yerine deformable ara yüzler uygulanmasına karar verilmiştir. Gerek remote displacement, gerekse remote force uygulamalarında temas yüzeyleri uygulamada çokça karşılaşılan çizgisel formda değil, 10'ar cm eninde gerçek alan (surface) tanımları yapılarak modellenerek gerçeğe yakın sonuçlar elde edilmesi sağlanmıştır. Analizler esnasında lineer olmayan analizlerle detaylı sonuçlar elde etmek adına, large deflections parametresi açık konuma getirilmiştir. Ayrıca yakınsama (convergence) hatası meydana gelmemesi için uygulanan yük tek kademede değil, 3 aşamada etkiyecek şekilde (load steps) artırılmıştır. Bu şekilde her kademede rijitlik matrisi bir sonraki yük kademesine geçmeden önce güncellenmiş de olmaktadır [9]. Analizler esnasında lineer olmayan tam Newton-Raphson iterasyon prosedürü ve otomatik zaman geçişi (automatic time stepping) ayarı yapılarak her iterasyonda model rijitlik matrisinin (stiffness matrix) güncellenmesi sağlanmıştır. Tüm bu parametre seçimleri akabinde yazılımın çözüm süresi oldukça artmıştır. Ancak bu şekilde ANSYS yazılımının geçmiş çözüm kayıtlarına dayanarak yeni yükleme adımlarını tahmin ve kontrol ederek, yakınsama (convergence) grafiğinin düzgünlüğü ölçüsünde yük adımlarını ilerletmesi sağlanmıştır. İterasyonlar esnasında yeterli yakınsama elde edilemezse rijitlik matrisi yenilenmekte ve yeterli yakınsama elde edilinceye kadar tekrarlanmaktadır [12]. Literatürde tolerans limitlerinin 0,05 ile 0,2 aralığında seçilmesi tavsiye edilmektedir [16].

\section{Bulgular}

Prototip traverslerin üretimi esnasında kullanılan betondan alınan $15 \times 15 \times 15$ cm'lik küp ve $15 \times 30$ cm'lik silindir numunelerin test sonuçlarına göre ortalama basınç dayanımı 77,3 MPa ve yarmada çekme dayanımı 4,66 MPa olarak belirlenmiştir. Betonun basınç dayanım sınıfı, TS EN 206-1 Çizelge 7 ve Çizelge 14 doğrultusunda C55/67 olarak belirlenmiş ve sonlu eleman analizlerinde karakteristik basınç dayanımı 55 MPa olarak tanımlanmıştır. TS 500:Şubat 2000 eşitlik 3.2'ye göre betonun elastisite modülü $38103 \mathrm{MPa}$ olarak hesaplanmıştır. Betonun karakteristik yarmada çekme dayanımı ise TS EN 206-1 Çizelge 16 doğrultusunda 4,16 MPa olarak, direkt (uniaxial) çekme dayanımı ise TS 500:2000 madde 3.3.2 doğrultusunda karakteristik yarmada çekme dayanımı değerinin 1,5'e bölünmesi ile 2,77 MPa olarak hesaplanmıştır. Traverslerde yapılan test sonuçları Tablo 1'de, örnek test görselleri ANSYS sonlu eleman analizlerinden elde edilen sonuçlarla karşılaştırmalı olarak Şekil 1, 2, 3, 4 ve 5'te sunulmuştur. Deney görsellerinde, çatlak gelişim mekanizması, yük kaldırıldıktan sonra kapanan (elastik) çatlaklar için mavi renkle, yük kaldırıldıktan sonra $0,05 \mathrm{~mm}$ ve daha fazla kalınlıktaki kalıcı (plastik) çatlak oluşması halinde ise kırmızı renkle gösterilmiştir. Şekil 1, 2, 3, 4 ve 5'ten görülebileceği üzere; traverslerde ilk çatlak 
$\left(\mathrm{Fr}_{\mathrm{r}}\right)$ 55-150 kN aralığında geniş bir aralıkta meydana gelebilmektedir. Bu ilk çatlak başlangıç değeri öngerilmeli traverslerde, öngerilme basıncının tükendiği noktayı belirlemek açısından önemli olup, EN 13230-6:2020 standardında ve literatürde belirtildiği ve demiryolu kuruluşlarının şartnamelerinde geçtiği üzere; demiryolu işletimi açısından öngerilmesiz traverslerde önem taşımamaktadır [17]. Şekil 1'den görülebileceği üzere; ANSYS yazılımıyla ilk çatlak başlangıcı gözlemlenen yük değeri $\left(\mathrm{Fr}_{\mathrm{r}}\right)$ analiz sonucunun, deneylerle yüksek yakınlıkla örtüştüğü görülmüştür. ANSYS analizi ile deneylerin örtüşmesi, betonun malzeme modeline ait parametrelerin yeterli doğrulukta olduğunun tespiti açısından önem taşımaktadır.

Tablo 1. TS EN 13230-3 Ray mesnedinde statik yüklemeli pozitif moment tayini deney sonuçları ve dünyadaki öngerilmeli ve öngerilmesiz emsallerinin karşılaştırılması

\begin{tabular}{lccc}
\hline Travers Numunesi Tanımı & $\begin{array}{c}\text { Ortalama çatlak } \\
\text { başlangıcı }(\mathrm{kN})\end{array}$ & $\begin{array}{c}\text { Ortalama 0,05 mm kalıcı } \\
\text { çatlak başlangıcı }(\mathrm{kN})\end{array}$ & $\begin{array}{c}\text { Ortalama kırılma } \\
\text { yükü }(\mathrm{kN})\end{array}$ \\
\hline 20 mm CFRP lamine & 89 & 215 & 344 \\
25 mm CFRP lamine & 130 & 250 & 360 \\
30 mm CFRP lamine & 135 & 283 & 363 \\
B70 tipi öngerilmeli travers [6] & 150 & 270 & 375 \\
U3 tipi öngerilmesiz travers [17] & $<100$ & $125-135$ & $175-200$ \\
\hline
\end{tabular}

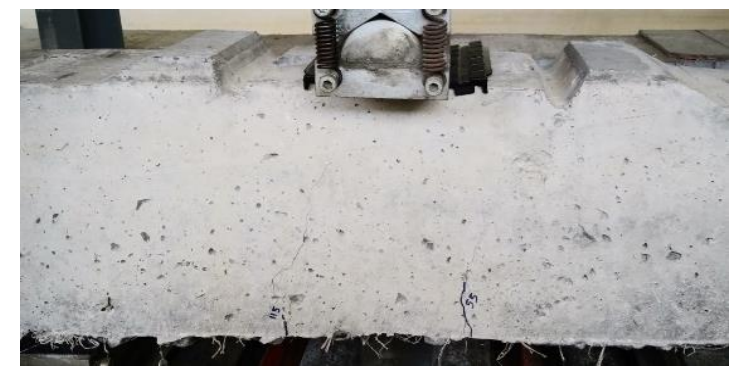

a) İlk çatlak yükü altında deney görseli

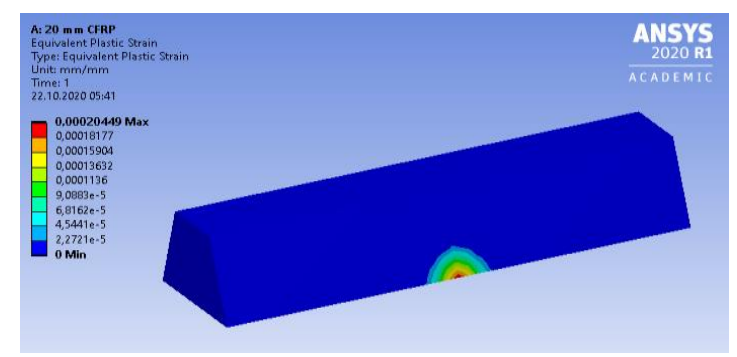

c) ANSYS Beton Plastic Strain Analizi

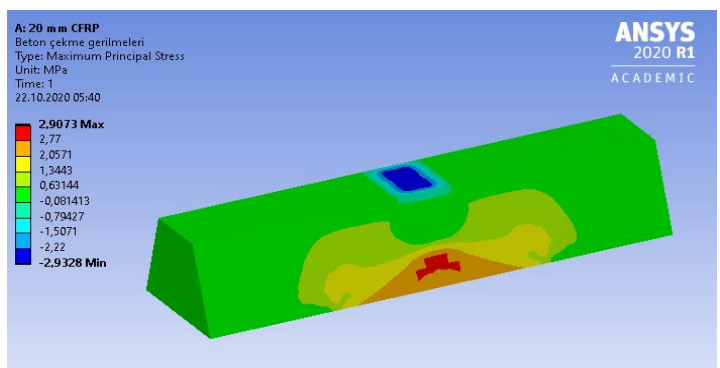

b) ANSYS Max. Principal Stress Analizi

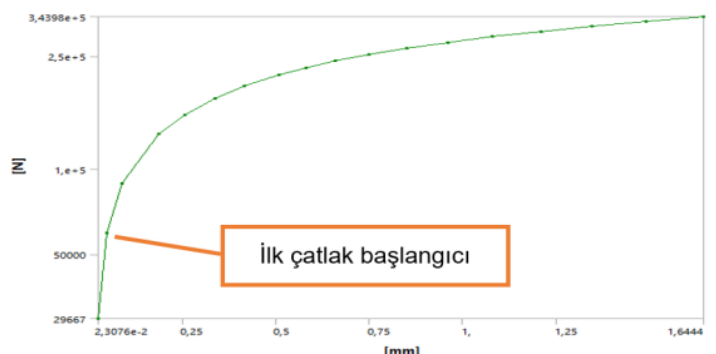

d) ANSYS yük-deformasyon eğrisi

Şekil 1. 20 mm CFRP plaka donatılı numune için ilk çatlak başlangıç yükü (Frr) deney ve ANSYS sonlu eleman analizi sonuçlarının karşılaştırması 
TS EN 13230-3'te istenen ikinci dizayn parametresi 0,05 mm kalıcı (plastik) çatlak meydana gelen yük değeridir $\left(\mathrm{Fr}_{0,05}\right)$. Deneylere göre mavi renkli geçici (elastik) çatlaklar yaklaşık 150$200 \mathrm{kN}$ düzeylerinde travers orta yüksekliğine, 200-300 kN dolaylarında da basınç lobunun üst kısmına kadar uzanmaktadır. Aynı süreçte basınç lobu altında $0,05 \mathrm{~mm}$ kalınlığında plastik çatlaklar başladığı tespit edilmiştir. $20 \mathrm{~mm}$ enindeki CFRP laminelerle donatılandırılmış traverslerde yapılan deneylerde söz konusu $\left(\mathrm{Fr}_{0,05}\right)$ yük ortalama $215 \mathrm{kN}$ olarak belirlenmiştir. $\mathrm{Bu}$ yük değeri ANSYS modeline uygulandığında, Şekil 2.b'de görüleceği üzere 0,05 mm'i geçen plastik deformasyonlar oldukça benzer bir şekilde elde edilmiştir. TS EN 13230-3'te istenen üçüncü ve son dizayn parametresi kırılma yüküdür $\left(\mathrm{Fr}_{\mathrm{B}}\right)$. Kırılma yükü ile yüklenen travers numuneleri ve ANSYS analizleri Şekil 3, 4 ve 5'te verilmiştir. Yapılan deneylerde, CFRP plakalarla donatılandırılmış traverslerde (çelik donatılı traverslerdekine benzer olarak) nihai dayanıma eğik kesme ve basınç lobu ezilmesi suretiyle erişilmiştir. Şekil 3'te $340 \mathrm{kN}$ düzeylerinde meydana gelen kesme ve eğik kesme çatlakları, Şekil 4'te ise $360 \mathrm{kN}$ düzeylerinde basınç lobu ezilmesi açık bir şekilde görülmektedir. Öngerilmesiz etriyeli çelik donatılar kullanılarak üretilen U3 tipi vb. traverslerin kırılma yükleri 175-200 kN düzeylerindedir [17]. Öngerilmeli B70 tipi traverslerde ise kırılma yük alt limiti 375 kN'dur [6].

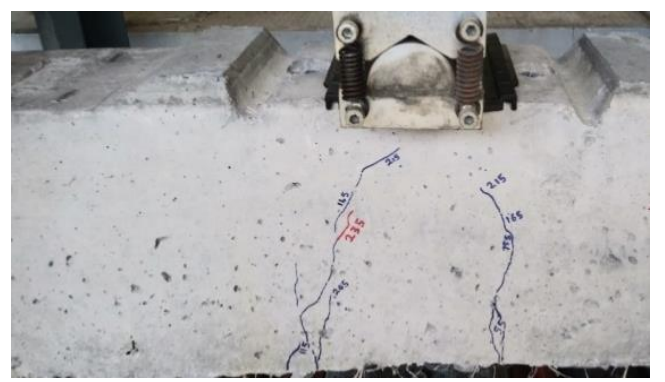

a) Fr0,05 (215 kN) yükünde deney görseli

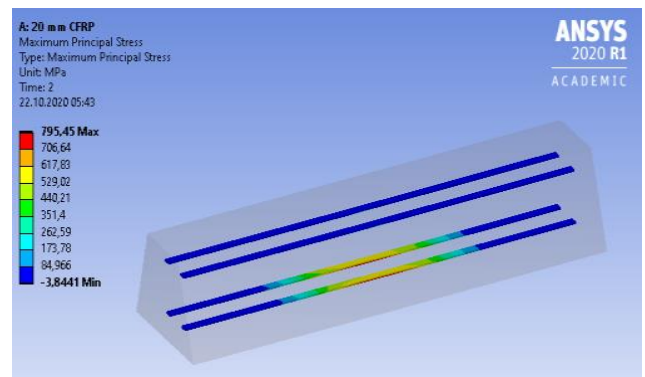

c) ANSYS Donatı von-Mises Analizi

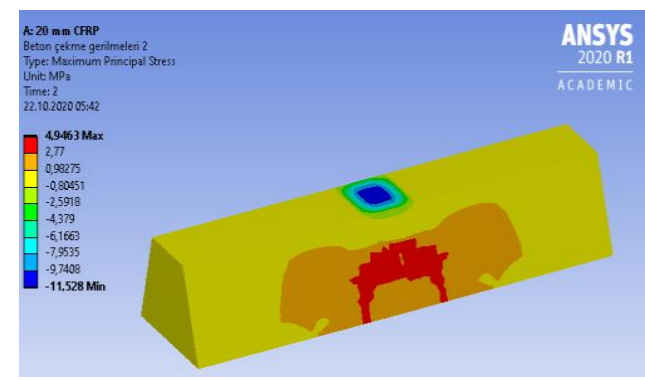

b) ANSYS Max. Principal Stress Analizi

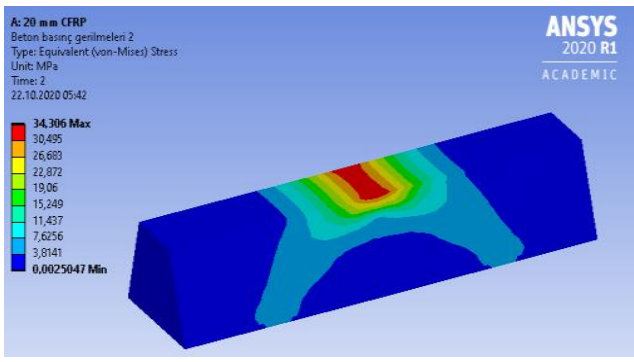

d) ANSYS Beton von-Mises Analizi

Şekil 2. $20 \mathrm{~mm}$ CFRP plaka donatılı numune için $0.05 \mathrm{~mm}$ kalıcı çatlak başlangıç yükü deney $\left(\mathrm{Fr}_{0,05}\right.$, ort. $215 \mathrm{kN}$ ) ve ANSYS sonlu eleman analizi sonuçlarının karşılaştırması 


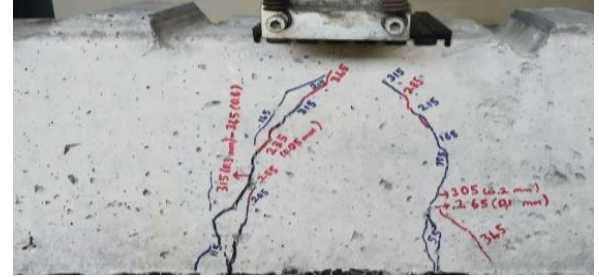

a) FrB (344 kN) yükünde deney görseli

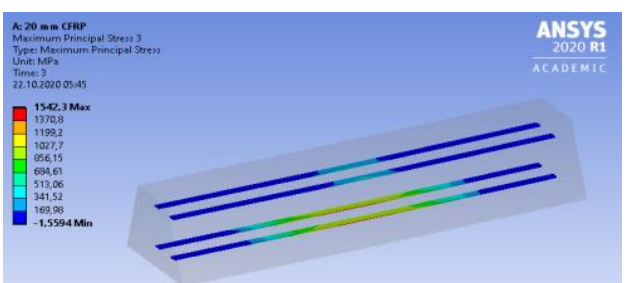

c) ANSYS Donatı von-Mises Analizi

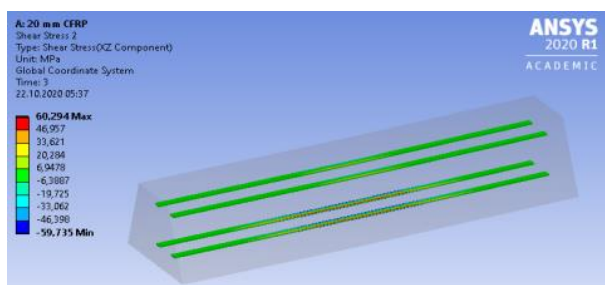

e) ANSYS Donatı Shear Stress Analizi

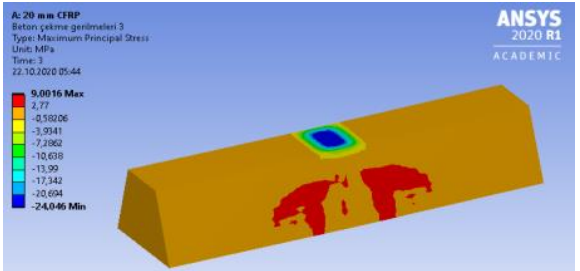

b) ANSYS Max. Principal Stress Analizi

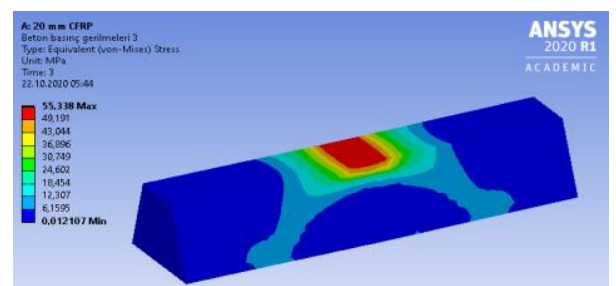

d) ANSYS Beton von-Mises Analizi

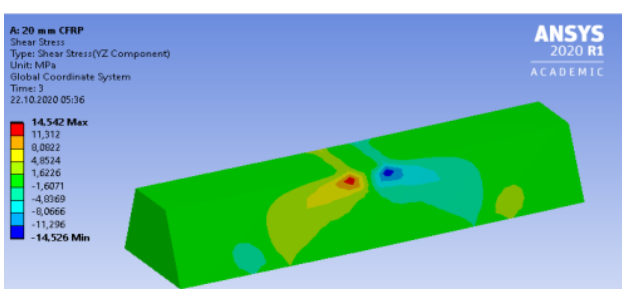

f) ANSYS Beton Shear Stress Analizi

Şekil 3. 20 mm CFRP plaka donatılı numune için kırılma yükü deney ( $\mathrm{Fr}_{\mathrm{B}}$, ort. $\left.344 \mathrm{kN}\right)$ ve ANSYS sonlu eleman analizi sonuçlarının karşılaştırması

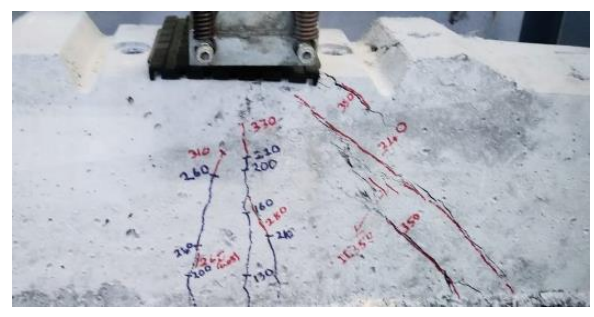

a) $\operatorname{FrB}(360 \mathrm{kN})$ yükünde deney görseli

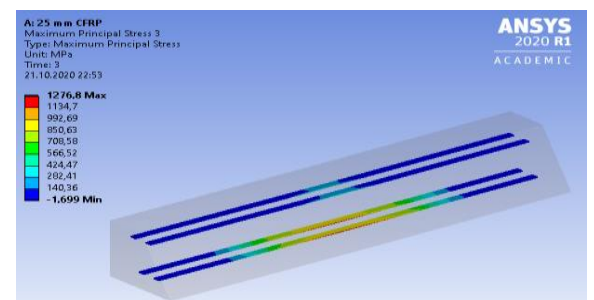

c) ANSYS Donatı von-Mises Analizi

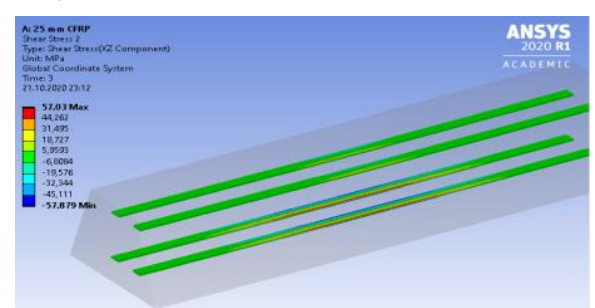

e) ANSYS Donatı Shear Stress Analizi

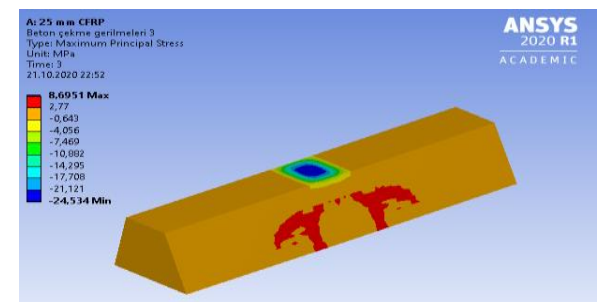

b) ANSYS Max. Principal Stress Analizi

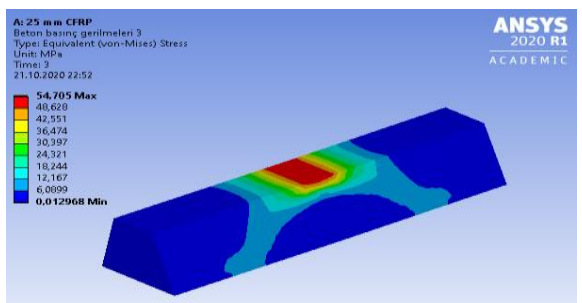

d) ANSYS Beton von-Mises Analizi

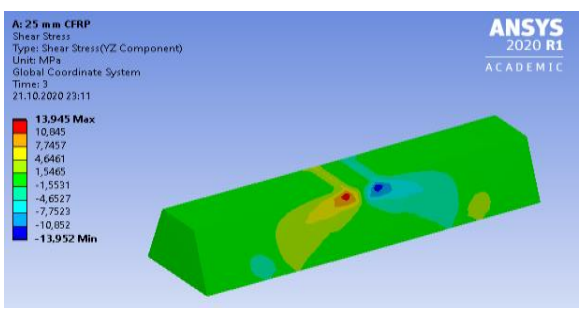

f) ANSYS Beton Shear Stress Analizi

Şekil 4. 25 mm CFRP plaka donatılı numune için kırılma yükü deney ( $\mathrm{Fr}_{\mathrm{B}}$, ort. $\left.360 \mathrm{kN}\right)$ ve ANSYS sonlu eleman analizi sonuçlarının karşılaştırması 


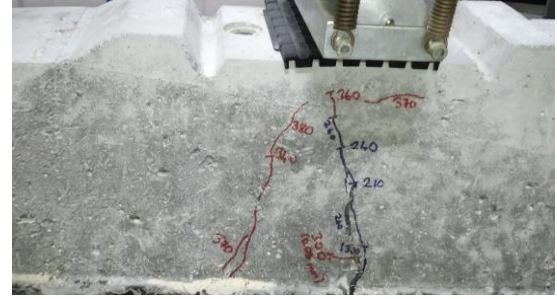

a) $\operatorname{FrB}(363 \mathrm{kN})$ yükünde deney görseli

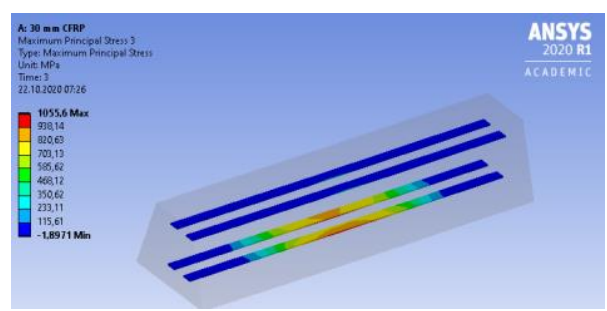

c) ANSYS Donatı von-Mises Analizi

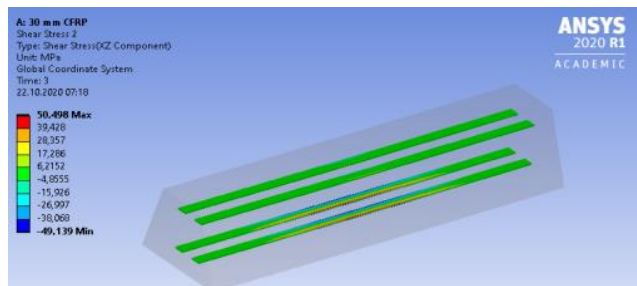

e) ANSYS Donatı Shear Stress Analizi

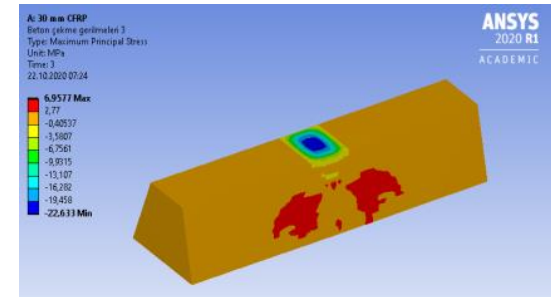

b) ANSYS Max. Principal Stress Analizi

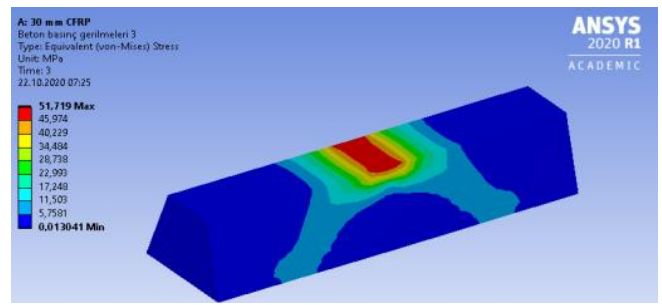

d) ANSYS Beton von-Mises Analizi

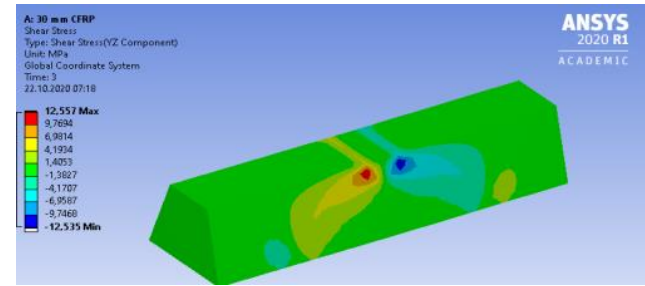

f) ANSYS Beton Shear Stress Analizi

Şekil 5. 30 mm CFRP plaka donatılı numune için kırılma yükü deney $\left(\operatorname{Fr}_{B}\right.$, ort. $\left.363 \mathrm{kN}\right)$ ve ANSYS sonlu eleman analizi sonuçlarının karşılaştırması

Analizler sonucunda ulaşılan önemli bir husus, $20 \mathrm{~mm}$ enindeki CFRP lamineler haricinde diğer prototiplerde, donatıların çekme dayanımının henüz tükenmediği, kırılmaların asıl nedeninin betonun (yaklaşı1 12-15 MPa'lık) kesme dayanımının ve ardından donatıların (maksimum 60 MPa'l1k) kesme dayanımlarının tükenmesidir. Nitekim yapılan deneyler esnasında her 3 donatı tipinde de 300-340 kN düzeylerinde traversin tüm kesitini boydan boya 45 derecelik açıyla geçen kesme çatlakları meydana gelmiştir. Deneyler esnasında ayrıca basınç lobunda ezilme ve/veya nihai kesme-eğik kesme çatlaklarıyla eş zamanlı olarak, kesme çatlak genişliğinin artması ile meydana gelen kaldıraç etkisiyle, CFRP plakaların gürültülü bir şekilde ezilme/sıyrılma davranış1 sergilemeye başladıkları görülmüştür. Fiber takviyeli polimer yapısı itibariyle tabakalar halinde göçme göstererek kalan kesitlerle travers halen yük taşımaya ve sehim yapmaya devam etmiştir. Görüldüğü üzere ANSYS modeli sayesinde kırılma mekanizması daha detaylı olarak anlaşllabilmektedir. Şekil 3.f, 4.f, 5.f'de beton kesme kapasitesinin tükendiği andaki gerilme dağılımı, Şekil 3.e, 4.e, 5.e'de ise CFRP plakalarda tabakalar halinde kesme kapasitesinin tükendiği andaki gerilme dağılımı görülebilmektedir.

Analizler sonucunda ulaşılan bir diğer husus, sonlu eleman analizlerinde gerilme analizlerinde sağlanan başarının aksine, deformasyon modellemesinde yeterli fayda elde edilememiştir. Şekil 1.d'de ANSYS yazılımı ile travers üzerine etkiyen yük ve travers tabanından ölçülen deformasyon ilişkisi sunulmuştur. Deformasyon sensörleri traverslerin eğilme açıklığının alt kısmının ortasında konumlandırılmıştır. Neticede yapılan analizlere göre maksimum yük altında dahi traverslerin 1,5-2 mm deformasyon yaptı̆̆ geldiği görülmüştür. Literatürde çokça tespit edildiği üzere gerek FRP donatılı gerekse çelik donatılı betonarme yapıların sonlu eleman analizlerinde deformasyon tahminleri, gerilme tahminleri kadar başarılı değildir [18]. Bu duruma donatılar ile beton arasında mükemmel aderans bulunduğu kabulü, kullanılan materyallerin homojen, izotropik, elastik-mükemmel plastik kabul edilmeleri, poisson oranının yükleme boyunca sabit kaldığı varsayımı, zamana bağlı sünme- 
büzülme-relaksasyon-sıcaklık değişimleri-korozyon vb. birçok faktörün hesaba katılmaması, yüklemeler esnasında özellikle betonda meydana gelen mikro-çatlaklar etkisiyle rijitliğinin değişmesi gibi birçok etken neden olmaktadır.

\section{Sonuç}

Çalışma sonucunda elde edilen çıktılar şu şekildedir:

- Tasarlanan traverslerde, ilk çatlak başlangıcının $\left(\mathrm{Fr}_{\mathrm{r}}\right)$ geniş bir aralıkta $(55-150 \mathrm{kN})$ meydana gelebildiği tespit edilmiştir. Bu değer öngerilmeli traverslerde, öngerilme basıncının tükendiği noktayı belirlemek açısından önemli olup, EN 13230-6:2020 standardında ve literatürde belirtildiği, ayrıca demiryolu kuruluşlarının şartnamelerinde geçtiği üzere; öngerilmesiz traverslerde demiryolu işletimi açısından önem taşımamaktadır.

- $0,05 \mathrm{~mm}$ kalıcı çatlak başlangıcının $\left(\mathrm{Fr}_{0,05}\right) 30 \mathrm{~mm}$ 'lik varyasyonda $283 \mathrm{kN}$ ile Avrupa hızlı tren hatlarında da kullanılan öngerilmesiz U3 tipi traverslerden \%115 daha yüksek dayanım gösterdiği ve öngerilmeli B70 tipi traverslerin minimum $270 \mathrm{kN}$ şartını da sağladığı tespit edilmiştir.

- Kırılma yükleri $\left(\mathrm{Fr}_{\mathrm{B}}\right)$ bakımından, 25 ve $30 \mathrm{~mm}$ CFRP donatı kullanılan varyasyonlarda benzer olarak $360 \mathrm{kN}$ ve $363 \mathrm{kN}$ değer elde edilmiş olup, bu değer U3 tipi traverslerin 175200 kN'luk kırılma yükü limitinden \%180 daha fazladır. Geliştirilecek traverslerin kalıp enkesit boyutlarındaki cüzi değişikliklerle öngerilmeli B70 tipi traverslerde istenen minimum 375 kN kırılma yükü şartını da sağlamasının mümkün olduğu düşünülmektedir.

- $\quad \mathrm{ANSYS}^{\circledR}$ yazılımı ile hazırlanan sonlu eleman modelinin gerçekleştirilen deneylerle büyük örtüşmeye sahip olduğu, elastik ve plastik çatlak başlangıcı ile nihai dayanıma erişilmesi esnasında beton ve donatılarda arka planda ne gibi gerilmeler meydana geldiğinin tahkiki için birçok avantaj sağladığı görülmüştür. Ancak sonlu eleman analizlerinde genellikle görüldüğü üzere; deformasyon miktarlarında yeterli örtüşme elde edilememiştir.

- Analiz ve deney sonuçlarına göre; CFRP donatı kesit alanı arttıkça, kırılma yükü artmasa dahi, kalıcı çatlak başlangıç yükünün $\left(\mathrm{Fr}_{0,05}\right)$ kayda değer düzeyde arttığı gözlenmiştir.

- Analizlere göre, en düşük donatı kesitine sahip 20 mm CFRP kullanılan traverslerde dahi, $\mathrm{Fr}_{0,05}$ yük değerinde, travers ray mesnedindeki beton malzeme yaklaşı $34 \mathrm{MPa}$ basınç gerilmesine (maksimum kapasitenin \%62'si), çekme lobundaki donatılar ise maksimum 795 $\mathrm{MPa}$ çekme gerilmesine (maksimum kapasitenin \%53’ü) maruz kalmıştır. Öngerilmeli traverslerde ise henüz tren yükleri tesir etmediği halde dahi, öngerilme kuvveti etkisiyle donatılarda yaklaşı $1100 \mathrm{MPa}$ gerilme (akma limitinin \%70'i) meydana gelmektedir. Bu nedenle öngerilmeli traverslerde yorulma esaslı dizayn yükü, ilk çatlak gözlemlenen $\mathrm{Fr}_{\mathrm{r}}$ yükü iken, öngerilmesiz traverslerde yaklaşık olarak $\mathrm{Fr}_{0,05}$ yükü olduğu literatürde belirtilmektedir.

- Analizler sonucunda ulaşılan diğer önemli bir husus, $20 \mathrm{~mm}$ enindeki CFRP lamineler haricindeki diğer prototiplerde, donatıların çekme dayanımının henüz tükenmediği, kırılmaların asıl nedeninin betonun yaklaşık 12-15 MPa'lık kesme dayanımının ve ardından CFRP donatıların maksimum $60 \mathrm{MPa}$ 'lık kesme dayanımının tükenmesidir. FRP ürünlerin birçok avantajı bulunmakla birlikte kesme dayanımlarının düşük olması gibi dezavantajları da mevcuttur. Bu yüzden yapılacak analizlerde kullanılan FRP'nin farklı doğrultularda farklı dayanım gösterdiği hususuna dikkat edilmelidir.

- Çalışmada kullanılan lamine formdaki CFRP donatılar, yüksek korozyon direnci, elektrik yalıtkanlığı ve manyetik nötrlük avantajlarının yanı sıra, dairesel alternatiflerine göre yaklaşık 9-10 kat daha düşük maliyete sahiptir. Bu sayede inşaat sektöründe yeni yeni kullanılmaya başlayan bu inovatif ürünler, çelik öngerilme donatılarından yalnızca \%30 daha yüksek hammadde maliyeti getirmektedir. Donatı maliyetleri arasındaki bu fark, travers temin maliyetinin \%5'inden azdır. Yeni prosesin öngerilmesiz, etriyesiz kolay üretim sağlaması ile işçilik, süre ve enerjiden sağlayacağı faydalar ile servis ömrü ve verimlilik bakımından sağlayacağı diğer daha önemli getirilerle avantajlı hale gelmesi mümkündür. 
Çalışmada incelenen yeni tip traverslerde, öngerilme uygulanmamasına ve etriye kullanılmamasına rağmen bu önemli avantajlara erişilmesi, yeni prosesin başarılı olabileceği kanaatini artırmaktadır. Ancak yeni bir travers modelinin geliştirilmesi için çok sayıda kombinasyon ile standartlarda istenen diğer deneylerin ve saha uygulamalarının da yapılması gerekmekte olup, bu çalışmalar imkanlar dahilinde devam etmektedir.

\section{Teşekkür}

Bu çalışma, TÜBITTAK Ardeb Dairesi Başkanlığı'nın 120M403/2020 sayılı projesi kapsamında desteklenmektedir. Ayrıca katkılarından dolayı TCDD Sivas Beton Travers Fabrikası Müdürü Sn. Ali KARABEY'e teşekkürlerimizi bildiririz.

\section{Kaynakça}

[1] J. Taherinezhad, M. Sofi, P. Mendis, T. Ngo, "Strain rates in prestressed concrete sleepers and effects on cracking loads," Electronic Journal of Structural Engineering, vol. 17, no. 1, pp. 65-75, January 2017.

[2] A. Jokūbattıs, G. Marc ‘ukaitis, J. Valivonis, "Influence of technological and environmental factors on the behavior of the reinforcement anchorage zone of prestressed concrete sleepers," Construction and Building Materials, vol. 121, part C, pp. 507-518, September 2016, doi: http://dx.doi.org/10.1016/j.conbuildmat.2016.06.025

[3] ACI-ASCE Committee 423, "State-of-the-art report on partially prestressed concrete, ACI 423.5R99,” 1999 [Online]. Avaliable: http://civilwares.free.fr/ACI/MCP04/4235r_99.pdf 1999.

[4] T. J. Barlo, A.D. Zdunek, "Stray current corrosion in electrified rail systems, northwestern university final report," 1995 [Online]. Avaliable: https://rosap.ntl.bts.gov/view/dot/13213/dot_13213_DS1.pdf

[5] H. Isozaki, J. Oosawa, Y. Kawano, R. Hirasawa, S. Kubota, S. Konishi, "Measures against electrolytic rail corrosion in Tokyo metro subway tunnels," Procedia Engineering, vol. 165, pp. 583 - 592, December 2016, doi: https://doi.org/10.1016/j.proeng.2016.11.754

[6] F. Çeçen, "Karbon - fiber donatıyla öngerilmesiz monoblok demiryolu beton traversi geliştirilmesi," Yüksek Lisans Tezi, Fen Bilimleri Enstitüsü, İnşaat Mühendisliği Ulaştırma ABD, Gazi Osman Paşa Üniversitesi, Tokat, 2019.

[7] F. Çeçen, B. Aktaş, "Yeni nesil demiryolu traversleri ve yerli FRP donatı kullanımının deneysel araştırmas1," Demiryolu Mühendisliği, vol. 13, pp. 53-64, January 2021, doi: https://doi.org/10.47072/demiryolu.803452

[8] K. D. Dalgıç, "Düşük elastisite modüllü cam lifli polimerle sargılanmış düşük dayanımlı betonun eksenel yükler altında davranışı ve sonlu eleman metodu ile analizi," Yüksek Lisans Tezi, İnşaat Mühendisliği Anabilim Dalı, İstanbul Teknik Üniversitesi, İstanbul, 2010.

[9] M. R. Hammad, "Non- linear finite element analysis of reinforced concrete beams strengthened with carbon fiber- reinforced polymer (CFRP) technique," Master of Science Thesis, Civil Engineering Department, The Islamic University of Gaza, 2015.

[10] G. Camata, E. Spacone, R. Zarnic, "Experimental and nonlinear finite element studies of RC beams strengthened with FRP plates," Composites: Part B., vol. 38, pp. 277- 288, 2007.

[11]Budapest University of Technology and Economics, Department of Applied Mechanics, "Index of / gyebro/files/ans_help_v182,” $2020 . \quad$ [Online]. Available: https://www.mm.bme.hu/ gyebro/files/ans_help_v182/ans_elem/Hlp_E_SOLID186.html [Accessed: 30.10.2020].

[12] A. J. Wolanski, "Flexural behavior of reinforced and prestressed concrete beams using finite element analysis," Master of Science Thesis, Marquette University, Milwaukee, Wisconsin, 2004.

[13] İ. Ovalı, ANSYS Workbench, İstanbul, Kodlab Yayın Dağıtım Yazılım ve Eğitim Hizmetleri San. ve Tic. Ltd. Şti., 3. Bask1, ISBN 978-605-9118-89-7, 2018.

[14]M. Shayanfer, A. Kheyroddin, M. S. Mirza, "Element size effects in nonlinear analysis of reinforced concrete members," Computers \& Structures, vol. 62, no. 2, pp 339-352, 1997.

[15]F. Duchaine, H. Champliaud, "Structured mesh generation by kriging with local refinement with a new elliptic schemel," Engineering with Computers, , vol. 23, no. 1, pp. 61-69, 2007.

[16] O. C. Zienkiewicz, R. L. Taylor, The finite element method for solid and structural mechanics, Butterworth-heinemann, ISBN: 9780080455587, 2005. 
[17]K. Giannakos, "Damage of railway sleepers under dynamic loads: A case history from the Greek railway network," Sixth International Conference on Case Histories in Geotechnical Engineering, Missouri University of Science and Technology, session 08-c, 2008, doi: http://scholarsmine.mst.edu/icchge/6icchge/session08c/5

[18] G. Tharmarajah, "Compressive membrane action in fibre reinforced polymer (FRP) reinforced concrete slabs," PhD Thesis, Queen's University, Belfast, 2010.

\section{Özgeçmiş}

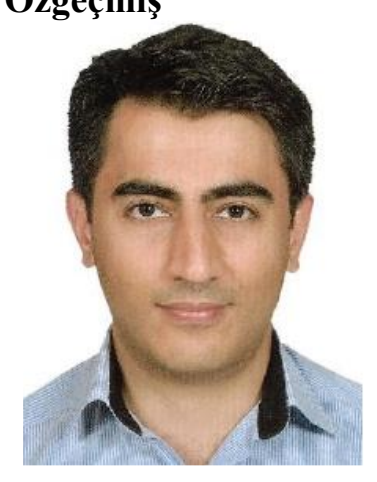

\section{Ferhat ÇEÇEN}

Yüksek Lisans eğitimini "Karbon - Fiber Donatıyla Öngerilmesiz Monoblok Demiryolu Beton Traversi Geliştirilmesi" teziyle Gaziosmanpaşa Üniversitesinde tamamlamış, halen Erciyes Üniversitesi'nde doktora eğitimine devam etmektedir. CFRP, GFRP ve çeşitli yerli ürünlerle milli demiryolu traverslerinin geliştirilmesi amaçlı ar-ge ve patent çalışmaları devam etmektedir.

E-Posta: ferhatcecen@tcdd.gov.tr

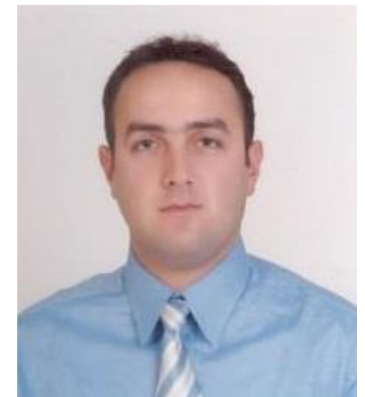

\section{Bekir AKTAŞ}

Lisans ve Yüksek Lisans eğitimini Erciyes Üniversitesi, Doktora Eğitimini ise Süleyman Demirel Üniversitesinde tamamlamış, halen Erciyes Üniversitesi İnşaat Mühendisliği Bölümü Ulaştırma Anabilim Dalında öğretim üyesidir. Ulaştırma alanında yerli ve yabancı dergilerde yayımlanan birçok makalesi bulunmaktadır.

E-Posta: baktas@erciyes.edu.tr

\section{Beyanlar:}

Bu makalede bilimsel araştırma ve yayın etiğine uyulmuştur.

Tüm yazarların eşit oranda katkısı olmuştur. 